\title{
Rare case of hematometra in rudimentary horn of unicornuate uterus after tubal ligation
}

\author{
Pundalik Sonawane*, Archana Waghela, Supriya Gaikwad
}

Department of Obstetrics and Gynecology, K. J. Somaiya Medical College and Hospital, Mumbai, Maharashtra, India

Received: 14 July 2018

Accepted: 06 August 2018

\section{*Correspondence:}

Dr. Pundalik Sonawane,

E-mail: drpundalik@gmail.com

Copyright: (C) the author(s), publisher and licensee Medip Academy. This is an open-access article distributed under the terms of the Creative Commons Attribution Non-Commercial License, which permits unrestricted non-commercial use, distribution, and reproduction in any medium, provided the original work is properly cited.

\begin{abstract}
Congenital anomalies of the uterus and vagina are associated with a high incidence of infertility and multiple obstetric problems. Unicornuate uterus with rudimentary horn is a rare mullerian duct anomaly of female genital tract with incidence of 1/100000. It usually develops following insufficient development of mullerian ducts. These patients present with dysmenorrhea, dyspareunia, and chronic pelvic pain because of endometriosis and rarely with acute abdominal symptoms following distention and torsion of the non-communicating rudimentary horn. A case of a unicornuate uterus with non-communicating rudimentary horn with functional endometrium developing hematometra after tubal ligation is presented herein.
\end{abstract}

Keywords: Hematometra, Non-communicating rudimentary horn, Tubal ligation, Unicornuate uterus

\section{INTRODUCTION}

Developmental anomalies of the müllerian duct system represent some of the most fascinating disorders that obstetricians and gynecologists encounter. Abnormal fusion of mullerian ducts, insufficient absorption of the fused mullerian duct or non-development or partial development of mullerian duct leads to various uterine abnormilities. ${ }^{1}$ The unicornuate uterus is caused by the nondevelopment of one mullerian duct, and the condition usually is associated with various degrees of rudimentary horn connected to the uterus when one of the ducts develops only partially. ${ }^{2}$ The rare form of these changes is the unicornuate uterus with a rudimentary horn. The frequency of congenital uterine anomalies in a fertile female population is about $1 / 200$ to $1 / 600$, whereas the frequency of rudimentary horn is $1 / 100 \quad 000 .^{3}$ This anatomical abnormality may lead to many gynecologic complications, such as endometriosis, primary infertility, and hematometra, anomalies of the urinary system and obstetrical problems, such as malpresentation, habitual abortion, and premature birth. ${ }^{2,4-6}$ Efficient planning of the therapeutic strategy is based on the effective diagnosis and clear categorization, in view of the numerous treatment options available for their management. The need for a reliable classification system is more than obvious. ${ }^{7}$ Usually these congenital anomalies of uterus present early with the beginning of menstrual life but in some cases they can be found out incidentally much later in life especially after or during some gynecological procedure. ${ }^{8}$

\section{CASE REPORT}

The patient was a 32-year-old female para 2, living 2 and 2 medical termination of pregnancy (P2L2MTP2) presented with severe dysmenorrhea requiring indoor admission treated with parenteral analgesics. Patient had a history of mini laparotomy sterilization 6 months back after which the patient experienced progressively 
increasing dysmenorrhea over period of 6 months. Patient was a known case of Mitral stenosis with open mitral commisurotomy performed in childhood.

On examination, patient's vital parameters were stable; abdomen was soft, mild tenderness was appreciated in right iliac fossa, healthy mini laparotomy scar was seen. Per-speculum examination showed cervix and vagina as healthy. On per vaginal examination, the uterus was anteverted and normal in size. A mass of about $3 \times 3 \mathrm{~cm}$ soft, mobile, tender was felt in right adnexa separate from uterus.

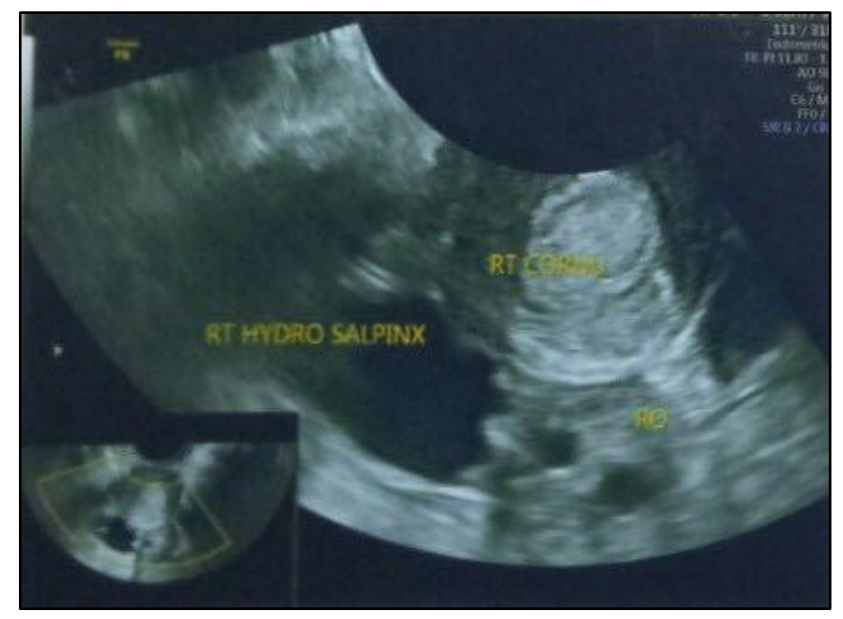

Figure 1: Ultrasonography of pelvis suggestive of hematometra with right sided hydrosalphinx.

Ultrasonography (USG) of pelvis and abdomen revealed unicornuate uterus on left side with $6.3 \times 4.5 \times 2.9 \mathrm{~cm}$ dimension with right sided rudimentary horn of size $4 \times 3 \mathrm{~cm}$ with collection in the cavity with echoes suggestive of hematometra with right sided hydrosalphinx close to the right horn (Figure 1). Both ovaries were normal.

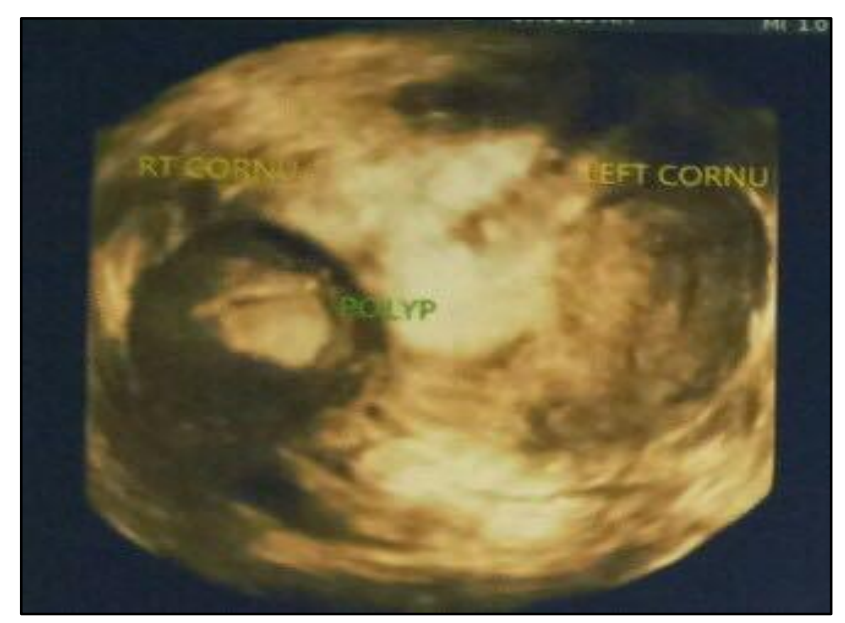

Figure 2: 3D ultrasonography of pelvis showing both cornu.
3D ultrasonography revealed unicornuate uterus with rudimentary horn with hematometra with right sided hydrosalphinx (Figure 2).

\section{Treatment}

Exploratory laparotomy was performed as patient was high risk for laparoscopy in view of her heart disease. Intraoperative findings revealed unicornuate uterus on left side with distended rudimentary horn of size $4 \times 3 \mathrm{~cm}$ distinctly separated from left unicornuate uterus by fibrous band with no obvious connection to it (Figure 3).

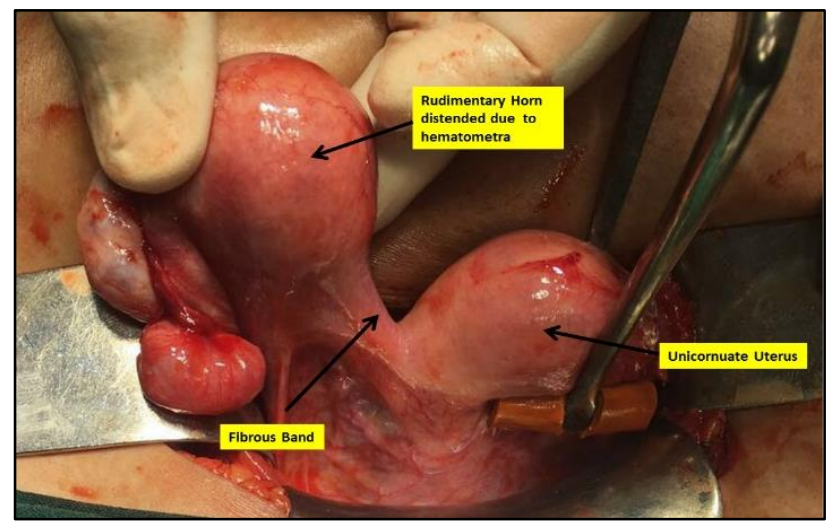

Figure 3: Non-communicating rudimentary horn $4 \times 3$ cm suspended by a fibrous band to the uterus visible on the left side.

No evidence of endometriosis noted. Bilateral tubal ligation site noted. Part of right fallopian tube proximal to tubal ligation site was swollen and edematous. Excision of right rudimentary horn with right sided fallopian tube performed. On cutting the specimen revealed chocolate colored fluid in rudimentary horn cavity suggestive of hematometra with no communication within the cavity to unicornuate uterus (Figure 4). Histopathology confirmed the diagnosis of uterine horn with endometrium within it with hematosalphinx. Intraoperative and postoperative period was uneventful.

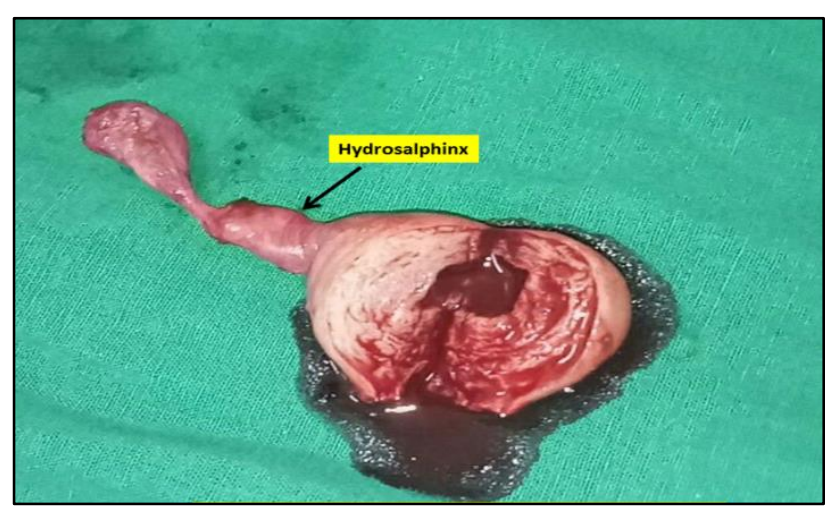

Figure 4: Cut section of the rudimentary horn showing hematometra with no communication within cavity. 


\section{DISCUSSION}

Most individual with a unicornuate uterus with rudimentary horn are asymptomatic because the rudimentary horn may be communicating or may not have functional endometrium. Symptoms of menstrual obstruction in non-communicating rudimentary horn with functional endometrium usually develop in initial few periods of menstruation after menarche. In present patient, since the patient had no symptoms of obstructive hematometra anytime previously, tubal ligation on right side rudimentary horn must have been performed with the assumption that either patient has the communication with the other horn cavity or may not have functioning endometrium. It may also be possible that rudimentary horn diagnosis must have been missed during mini laparotomy tubal ligation.

Present patient had a non-communicating rudimentary horn with little functioning endometrium. With communication of this rudimentary horn via fallopian tube into the peritoneal cavity there was no obstruction to menstrual flow despite of no communication to other horn and had no symptoms of obstructive hematometra till the procedure of tubal ligation was performed. After performing tubal ligation, patient had obstruction of menstrual fluid through fallopian tube with hematometra in the rudimentary horn, resulting in progressively severe dysmenorrhea.

Robischon $\mathrm{K}$ et al presented a case similar to ours where the patients' anomaly was found out only after detection of hematometra after tubal ligation. ${ }^{9}$ Her normal reproductive history and lack of any prior pain symptoms are in sharp contrast to the usual presentation of unicornuate uterus with non-communicating functional horn patients. ${ }^{10,11}$ Lee CY et al, presented a case where 6 years after tubal ligation, the patient developed dysmenorrhea in 10 months prior to admission. They attributed it to the functional endometrial debris which obstructed the communication tract of rudimentary horn after tubal ligation. ${ }^{12}$

Optimal management for rudimentary horn depends on the history and specific laparoscopic findings. In asymptomatic patients the lack of readily available noninvasive diagnostic method to detect both, the communication between rudimentary horn and unicornuate uterus and presence of small functional endometrium in rudimentary horn further delays the management of rudimentary horn. Especially for the younger women in the fertile period as in present case, the rudimentary horn must be excised because such intervention will also prevent possible endometriosis development. Authors suggest that while performing tubal ligation in asymptomatic patients with rudimentary horn, discuss with patient the option of either removal of non-communicating rudimentary horn during tubal ligation or the possibility of development of this rare iatrogenic complication if tubal ligation is done on the side of non-communicating rudimentary horn.

Funding: No funding sources Conflict of interest: None declared

Ethical approval: Not required

\section{REFERENCES}

1. Syed I, Hussain HK, Weadock W, Ellis J. Uterus, Mullerian duct abnormalities. An Online Rev Art Emed Webs. 2002 Aug 13.

2. Adhesions A. The American Fertility Society classifications of adnexal adhesions, distal tubal occlusion, tubal occlusion secondary to tubal ligation, tubal pregnancies, Mullerian anomalies and intrauterine adhesions. Fertil Steril. 1988;49(6):944.

3. Atmaca R, Germen AT, Burak F, Kafkasli A. Acute abdomen in a case with noncommunicating rudimentary horn and unicornuate uterus. JSLS: J Soc Laparoendoscop Surg. 2005 Apr;9(2):235.

4. Chan YY, Jayaprakasan K, Zamora J, Thornton JG, Raine-Fenning N, Coomarasamy A. The prevalence of congenital uterine anomalies in unselected and high-risk populations: a systematic review. Human Reprod Update. 2011 Jun 24;17(6):761-71.

5. Grimbizis GF, Camus M, Tarlatzis BC, Bontis JN, Devroey P. Clinical implications of uterine malformations and hysteroscopic treatment results. Human Reprod Update. 2001 Mar 1;7(2):161-74.

6. Saravelos SH, Cocksedge KA, Li TC. Prevalence and diagnosis of congenital uterine anomalies in women with reproductive failure: a critical appraisal. Human Reprod Update. 2008 Jun 6;14(5):415-29.

7. Grimbizis GF, Campo R. Congenital malformations of the female genital tract: the need for a new classification system. Fertil Steril. 2010;94(2):401-7.

8. Chang CY, Chang SY, Changchien CC, Lui CC, Huang HW. Hematometra of the rudimentary horn of a unicornuate uterus resulting from cesarean section. Am J Obstet Gynecol. 2001 Nov 1;185(5):1263-4.

9. Robischon K, Baram DA, Phipps WR. Presentation of a Müllerian anomaly with outflow obstruction after tubal ligation. Fertil Steril. 1996;65(4):866-8.

10. Buttram Jr VC, Gibbons WE. Müllerian anomalies: a proposed classification (an analysis of 144 cases). Fertil Steril. 1979 Jul 1;32(1):40-6.

11. Heinonen PK. Clinical implications of the unicornuate uterus with rudimentary horn. Int J Gynecol Obstet. 1983 Apr 1;21(2):145-50.

12. Lee CY, Cheng WC, Hwang JL. Delayed severe dysmenorrhea after tubal ligation in a patient with rudimentary horn: a case report. Taiwanese J Obstet Gynecol. 2005 Mar 1;44(1):87-90.

Cite this article as: Sonawane $\mathrm{P}$, Waghela A, Gaikwad S. Rare case of hematometra in rudimentary horn of unicornuate uterus after tubal ligation. Int J Reprod Contracept Obstet Gynecol 2018;7:3881-3. 